Article

\title{
Evaluating the Efficacy of Point-of-Use Water Treatment Systems Using the Water Quality Index in Rural Southwest China
}

\author{
Zejin Zhang ${ }^{1}$, Wei Zhang ${ }^{1, *}, \mathrm{Xi} \mathrm{Hu}^{1}{ }^{1}$, Kexin $\mathrm{Li}^{2}{ }^{2}$, Pengfei Luo ${ }^{1}$, $\mathrm{Xin} \mathrm{Li}^{1}$, Wen $\mathrm{Xu}^{1}$, Shiyu $\mathrm{Li}^{1,3,4, *}$ \\ and Changqun Duan $1,3,4, * \mathbb{D}$ \\ 1 School of Ecology and Environmental Science, Yunnan University, Kunming 650091, China; \\ zjzhang@mail.ynu.edu.cn (Z.Z.); huxi@mail.ynu.edu.cn (X.H.); pfluo@mail.ynu.edu.cn (P.L.); \\ xinli@mail.ynu.edu.cn (X.L.); surexu@mail.ynu.edu.cn (W.X.) \\ 2 Institute of International Rivers and Eco-security, Yunnan University, Kunming 650091, China; \\ likexin@mail.ynu.edu.cn \\ 3 Yunnan Key Laboratory for Plateau Mountain Ecology and Restoration of Degraded Environments, \\ Yunnan University, Kunming 650091, China \\ 4 International Cooperative Center of Plateau Lake Ecological Restoration and Watershed Management of \\ Yunnan, Yunnan University, Kunming 650091, China \\ * Correspondence: 20050156@ynu.edu.cn (W.Z.); lisy@ynu.edu.cn (S.L.); chqduan@ynu.edu.cn (C.D.)
}

Received: 14 February 2020; Accepted: 18 March 2020; Published: 20 March 2020

check for updates

\begin{abstract}
Rural China faces a shortage of safe drinking water. There are significant challenges associated with small centralized water supply systems and decentralized water supply systems. Many rural residents use point-of-use water treatment systems to ensure the safety of their drinking water. The actual water purification effect and applicability of these water treatment systems in small centralized and decentralized water supply systems need to be determined urgently. In this study, the water quality index (WQI) method was applied for the first time in rural areas to evaluate the effectiveness of point-of-use water treatment systems. A total of 67 reverse osmosis water treatment systems were tested. The rate of compliance with drinking water standards of the decentralized water supply was low (37\%). Compared with untreated water, the use of a reverse osmosis water treatment system improved the rate of compliance with drinking water standards, but this effect was not satisfactory $(8 \%)$. Among the factors potentially affecting the purified water quality of point-of-use water treatment systems (e.g., service time of the water treatment system, service time of the filter element, and type of water source), the service time of the filter element had the most significant influence on the water quality. If the filter element had not been replaced for a long period, the removal effect of the water treatment system on the total hardness, sulfide, copper, and ammonia nitrogen was significantly affected, reducing the quality of the purified water. To ensure the safety of drinking water, it is recommended to replace the filter element of a reverse osmosis water treatment system at least once a year.
\end{abstract}

Keywords: water quality; reverse osmosis; drinking water; household water treatment devices; small centralized water supply; decentralized water supply

\section{Introduction}

Access to adequate and safe drinking water is considered a basic human right and a guarantee to human health and sustainable development [1-3]. Improving access to safe drinking water is one of the most important sanitation infrastructure projects worldwide [1,4-6]. However, with increasing water pollution and the uneven distribution of water treatment facilities, the safety of China's drinking 
water is facing significant challenges [7-11]. Compared with almost all cities with well-equipped water treatment facilities, more than 200 million people in rural China lack access to safe drinking water due to inadequate drinking water treatment systems [10,12,13].

In recent years, in developing countries, small household water purification systems have gradually become widely used by consumers [14-17]. Increasing numbers of Chinese villagers are installing and using water treatment systems to maintain safe and healthy drinking water. Studies have shown that point-of-use water treatment systems can effectively reduce the risk of drinking water contamination [14,17]. Among these water treatment systems, reverse osmosis water treatment systems, which consist of a water pump, front filter (PP cotton column and activated carbon adsorption column), reverse osmosis filter element, rear filter (mostly activated carbon adsorption column), and water faucet [18], are widely used for treatment of domestic drinking water [16]. However, in China, most point-of-use water treatment systems have been designed to filter urban drinking water supplied by a centralized water supply. The applicability of these water treatment facilities in decentralized water supply models in rural areas is unclear. At the same time, it is difficult for users to judge the effect of a point-of-use water treatment system directly [19]; thus, it is of practical significance to investigate the actual effect and applicability of these systems.

On the other hand, China has adopted the "Sanitary Standard for Drinking Water" (GB5749-2006) [20] to evaluate the quality of drinking water. This standard uses the single parameter method (i.e., if one parameter exceeds the drinking water standard, the drinking water is considered not to be compliant with the standard) to determine the compliancy of the water sample with the standard. As a result, it can only be concluded that the drinking water is "compliant with the standard" or "not compliant with the standard", and the number of parameters exceeding the guidelines and the extent of their exceedance cannot be determined. As an effective mathematical tool, the water quality index (WQI) takes into account complex water quality measurements to obtain a numerical score reflecting the overall water quality status $[21,22]$. This score can indicate water quality issues or the suitability of water use [21,22]. In recent years, due to its intuitive and dimensionless characteristics, the WQI has been used by researchers to evaluate the quality of surface water and groundwater [23-31]. However, the WQI has not been used to evaluate domestic water treatment systems in small centralized or decentralized water supply systems.

In this study, we first compared the water flowing from a household faucet (raw water, i.e., water received by residents without point-of-use water treatment) and the water flowing from a faucet from a point-of-use water treatment system (purified water). The impact of using a water treatment system on water quality parameters under the conditions of a small centralized water supply and a decentralized water supply system in rural areas of the plateau mountains of Yunnan Province was evaluated. To facilitate the evaluation, we applied a WQI calculation method that identifies the number of water quality parameters responsible for the drinking water standard exceedance and the extent of the exceedance [20,32]. Then, we adopted "Parameters predominantly meet acceptable levels. No acute threat to human health." (i.e., WQI $<1$ ) was the key criterion and we applied a regression analysis method to analyze the factors that potentially affect rural point-of-use water treatment systems (e.g., system use time, filter element use time, etc.). Finally, based on the factors that had the greatest influence on the domestic water treatment system (the service time of the filter element), the efficiency of removing various water quality parameters by the rural point-of-use water treatment system was analyzed, and suggestions were made for the correct use of a point-of-use water treatment system.

\section{Materials and Methods}

\subsection{Study Region and Water Supply Systems}

The study area occupied three counties of the Dali Bai Autonomous Prefecture, Yunnan Province, southwestern China: Binchuan County, Xiangyun County, and Wuyuan County. This region has a northern subtropical plateau monsoon climate, and the average annual rainfall is $1041.2 \mathrm{~mm}$. The 
terrain is complex with higher elevations in the northwest and lower elevations in the southeast. There are two main types of water resources in the area, namely surface water and groundwater. Rural drinking water sources are all derived from shallow groundwater. Water supply systems included: (1) a small centralized water supply where the rural centralized water supply system serves a population of less than 10,000 people, in which pumped water is stored in an elevated water tank and then piped into a water treatment system and (2) a decentralized water supply in which individual users draw water directly from wells and store it in a water tank in their homes, with wastewater flowing into a water treatment system under gravity. Within the three counties of the study area, 28 villages were selected for sampling to capture the diversity of the topography and population distribution, in addition to the type of water supply systems (i.e., small centralized and decentralized, Figure 1).

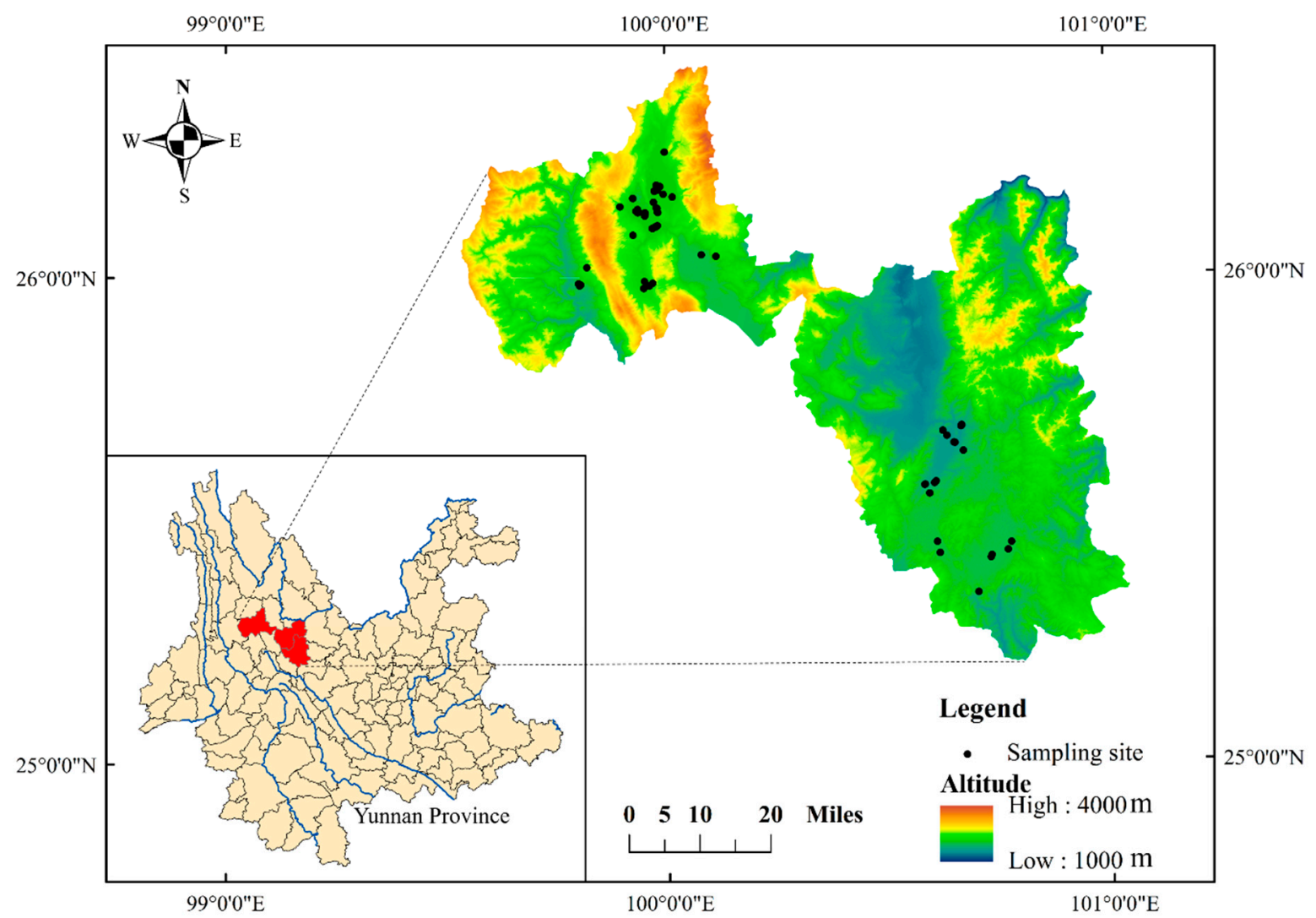

Figure 1. Location of the sampling sites in Yunnan Province, China.

\subsection{Survey and Water Sampling}

A questionnaire-type survey regarding the use of water treatment systems was conducted via consultation with village committees and household visits. Surveys were conducted in accordance with professional ethics while respecting the voluntary participation and privacy of the interviewees [2]. First, we confirmed the distribution and usage rate of household water treatment systems in the village and then randomly selected one to four volunteers to conduct a questionnaire survey. The questionnaire included items pertaining to the: (1) water treatment system brand and process type, (2) water treatment system service time, (3) filter element service time after installation in the water treatment system, (4) water supply system, and (5) treatment method used before drinking. All questions were answered by the homeowners. A total of 67 questionnaires were collected.

Samples of both the raw/untreated water (i.e., before treatment in a water treatment system) and the water treated by water treatment systems were collected. The raw water (RW) and purified water (PW) sampling points are shown in a schematic diagram of a typical water treatment system (Figure 2). Local residents take water several times a day from the water outlet (usually a faucet) of the 
water treatment system when they need to drink or cook. We simulated a single water intake process (i.e., a random water sample was taken from the water treatment systems), and the water sampling time was from 9:00 a.m. to 7:00 p.m. every day. We followed the relevant guidelines pertaining to the collection and storage of water samples provided in the "Chinese standard measurement methods for drinking water" (GB/T 5750-2006) [33]. To improve the consistency of the sample with the water use habits of the population in the study area, we opened the water faucets of the water treatment systems and took $1 \mathrm{~L}$ of water directly (the water treatment systems were not flushed before sampling). The water sample was poured into two containers $(0.5 \mathrm{~L}$ glass bottles for measuring chemical oxygen demand (COD) and total organic carbon (TOC) and $0.5 \mathrm{~L}$ polyethylene plastic bottles for measuring other parameters). The bottles were kept refrigerated, and water samples were transported to the laboratory for testing within two days. According to the product specification and process flow of the water treatment systems, all 67 systems sampled were determined to be reverse osmosis water treatment systems.

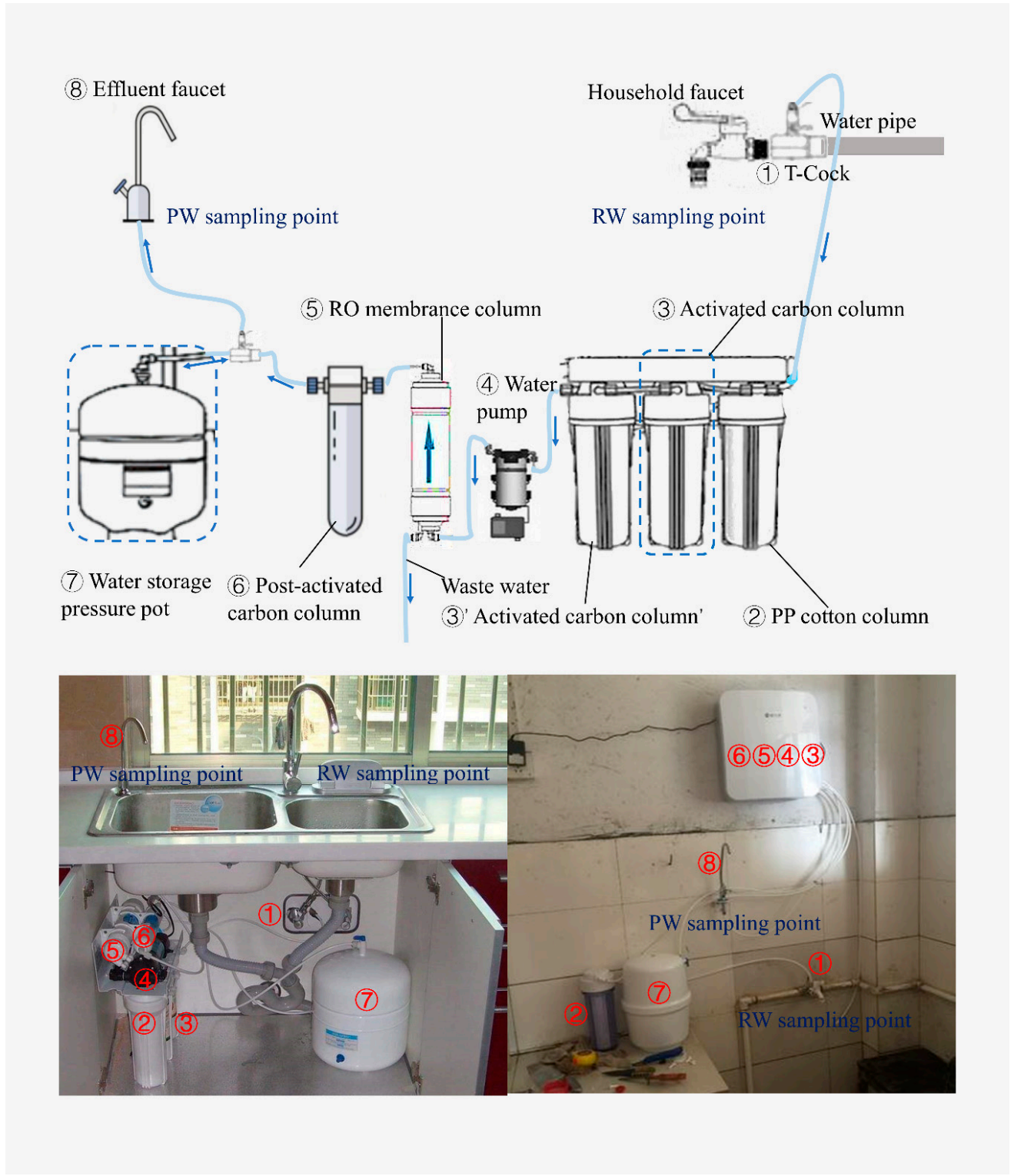

Figure 2. Schematic diagram and photographs showing the typical installed water treatment system (the dotted line indicates that this component is only available on some devices, and the numbers on the two photographs show the corresponding components in two systems). 
Onsite measurements of the water samples included water temperature, $\mathrm{pH}$, total dissolved solids, odor and taste, and visible objects. A portable turbidity meter HACH 2100Q (HACH, Loveland, CO, USA) was used to measure turbidity to evaluate the precipitation of organic matter and other suspended matter in the water. Total dissolved solids were measured to evaluate the degree of mineralization of the water using a portable total dissolved solids meter INEAS DDBJ-350F (INEAS, Shanghai, China). The $\mathrm{pH}$ was measured using a portable $\mathrm{pH}$ meter INEAS pHBJ-260 (INEAS, Shanghai, China) calibrated using standard buffers of $\mathrm{pH} 4.0$ and 7.0. Water samples were returned to the laboratory in time to test other parameters. Details of the test methods and grading standards for the parameters odor/taste and visible objects are shown in Table S1.

\subsection{Analytical Methods and Evaluation Standards}

Referring to China's Sanitary Standards for Drinking Water (GB5749-2006) [20], 15 parameters were selected. The sensory and general chemical parameters were odor and taste, visible objects, color, turbidity, $\mathrm{pH}$, total dissolved solids, iron, and total hardness. The organic pollution parameters were oxygen consumption, TOC, sulfide, and ammonium nitrogen. The toxicity parameters were copper, hexavalent chromium, and nitrate nitrogen. The reason for the absence of other parameters (e.g., arsenic, fluorine, and microorganisms) is discussed in the supplementary materials.

The standard values used for total dissolved solids, total hardness, ammonia nitrogen, COD, iron, nitrate nitrogen, and $\mathrm{pH}$ were those specified in the "Rural small-scale centralized water supply and decentralized water supply" section of China's Sanitary Standards for Drinking Water (GB5749-2006) [20]. The TOC standard value used was the reference index of drinking water quality, and the standard values of the other indexes used were the conventional detection indexes, which were all provided in the standard.

\subsection{The WQI and Classification}

The commonly used methods to calculate the WQI include the comprehensive index method [23,30,32], entropy weight method [28], fuzzy evaluation method [26], weighted superposition analytical method [27], and an artificial neural network [34]. In this study, we selected a WQI calculation method including "punitive terms" for items exceeding the standards, which is suitable to reflect the quantity and extent of standard exceedances for various drinking water quality parameters [32] (for the calculation basis and detailed process see the Supplementary Materials).

Formula (1) was used to calculate each single index $\left(I_{i}\right)$ except $\mathrm{pH}$ :

$$
I_{i}=C_{i} / S_{i}
$$

where $I_{i}$ is the single index, $C_{i}$ is the individual test result, and $S_{i}$ is the standard value (the standard value for each parameter according to China's Sanitary Standards for Drinking Water (GB5749-2006) [20]) of the index. If $C_{i}$ is below the detection limit or $<0.1 S_{i}$, the assignment value $I_{i}=0.1$. If visible objects are detected, $I_{i}=1.50$; if not, $I_{i}=0.10$. Odor and taste were taken as a single index $I_{i}$ according to the detection level (scale of $0-5$ ). The test methods and grading standards for visible objects and odor/taste are shown in Table S1. Formula (2) was used to calculate the $\mathrm{pH}$ index $\left(I_{p H}\right)$ :

$$
I_{p H}=\left|C_{p H}-\left(S_{\max }+S_{\min }\right) / 2\right| /\left|S_{\max }-\left(S_{\max }+S_{\min }\right) / 2\right|
$$

where $I_{p H}$ is the $\mathrm{pH}$ index (expressed as a single index value), $C_{p H}$ is the $\mathrm{pH}$ test result, $S_{\max }$ is the standard upper limit (9.5), and $S_{\min }$ is the standard lower limit (6.5). Formula (3) was used to calculate the WQI:

$$
\mathrm{WQI}=\sqrt{\left(\sum_{i=1}^{n} I_{i}\right) / n} \times \sqrt{I_{i, \max }} \times \prod I_{i, \text { exceed }}
$$


where $n$ is the sample size, $I_{i, \max }$ is the maximum index value, and $I_{i, \text { exceed }}$ is the value of the items exceeding the standard of a single index (i.e., parameters that can potentially cause harm). Therefore, all $I_{i}>1$ are $I_{i \text {,exceed }} I_{i \text {,exceed }}$ is not calculated when all $I_{i}<1$. $\Pi$ is the continuous multiplication of all $I_{i, \text { exceed }}$ values.

Based on the calculated WQI value, the drinking water quality was graded according to the degree of compliance with Chinese drinking water standards [20], as shown in Table 1 [25,28,29,32,35-37].

Table 1. Classification of drinking water quality based on the WQI $[20,36,37]$.

\begin{tabular}{ccc}
\hline Rank & WQI Range & Suggested Interpretation \\
\hline 1 & WQI $\leq 1$ & $\begin{array}{c}\text { Parameters predominantly meet acceptable levels. } \\
\text { No acute threat to human health. }\end{array}$ \\
2 & $1<$ WQI $\leq 5$ & $\begin{array}{c}\text { Parameters occasionally exceed the acceptable levels. } \\
\text { Low threat to human health. }\end{array}$ \\
4 & $25<$ WQI $\leq 25$ & $\begin{array}{c}\text { Parameters sometimes exceed the acceptable levels. } \\
\text { Moderate threat to human health. }\end{array}$ \\
5 & WQI $>50$ & $\begin{array}{c}\text { Parameters often exceed the acceptable levels. } \\
\text { Marked threat to human health. } \\
\text { Most parameters exceed the acceptable levels. } \\
\text { Severe threat to human health. }\end{array}$ \\
\hline
\end{tabular}

\subsection{Average Removal Rate}

The average removal rate (RR, \%) for each pair of raw and purified water parameters was calculated as follows:

$$
\mathrm{RR}=\left[\sum_{i=1}^{n}\left(C_{i r}-C_{i p}\right) / C_{i r}\right] / n \times 100 \%
$$

where $C_{i r}$ is the individual test result of the raw water parameter, $C_{i p}$ is the individual test result of the purified water parameter corresponding to $C_{i r}$, and $n$ is the number of water treatment systems included in the calculation. In this study, $n=67$. When $C_{i r}$ is below the detection limit (or $C_{i r}=0$ ), and $C_{i p}$ is higher than the detection limit, the RR is defined as $-1000 \%$. When $C_{i r}$ is below the detection limit (or $C_{i r}=0$ ), and $C_{i p}$ is also below the detection limit (or $C_{i p}=0$ ), the RR is defined as $0 \%$. If the removal rate is positive (negative), the parameter concentration decreases (increases). Details of the RR calculation Formula and examples of the RR calculation are shown in the supplementary materials.

\subsection{Statistical Analysis}

The data were compiled using Excel 2013, statistical analyses were performed using SPSS 19.0 and $\mathrm{R}$, and visualization was conducted using the ggplog2 package of $\mathrm{R}$. The paired rank-sum test was used to determine differences between raw water and purified water quality parameters in paired samples. The chi-squared $\left(\chi^{2}\right)$ test was used to compare the qualified rates of raw water and purified water in different groups. The factors influencing the WQI of purified water were determined using a binary logistic regression model. $p<0.05$ was considered statistically significant.

\section{Results and Discussion}

\subsection{Survey Results}

A total of 67 valid questionnaires were collected in this study. In the study area, three to four people typically shared the same water treatment system. All of the water treatment systems were based on reverse osmosis technology. Among the responding households, 28 (42\%) had a decentralized water supply, whereas 39 (58\%) had a small centralized water supply. The service life of the purifier was $\leq 2$ years in 39 (58\%) households and $>2$ years in $28(42 \%)$ households. The filter element of the water treatment systems had been used for $\leq 1$ year in $38(57 \%)$ households and $>1$ year in $29(43 \%)$ 
households. A total of 65 (97\%) villagers reported using purified water as drinking water, and $42(65 \%)$ boiled the water before drinking (Tables S2 and S3).

\subsection{Water Quality Results}

According to China's Sanitary Standards for Drinking Water (GB5749-2006) [20], if one or more of the 15 parameters tested failed to meet the standard, it was determined that the water sample did not comply with drinking water standards. A total of $25(37 \%)$ raw water samples complied with drinking water standards. None of the samples had any detectable odor/taste or visible objects. The color, turbidity, total dissolved solids, copper, TOC, and $\mathrm{pH}$ did not exceed their standard values. The remaining indexes exceeded their standard values to varying degrees. Among them, ammonia nitrogen exceeded the standard value most frequently ( $42 \%)$, followed by hardness $(18 \%)$ and COD $(10 \%)$ (Table 2, Table S2). This indicates that the small centralized and decentralized water supplies in the plateau mountainous area of Dali Bai Autonomous Prefecture have high levels of organic pollution, rendering the overall water quality unsatisfactory.

Table 2. Paired rank-sum test and the rates of water quality exceedance for parameters of the raw water RW and purified water (PW) samples $(n=67)$.

\begin{tabular}{|c|c|c|c|c|c|}
\hline \multirow{2}{*}{ Parameter } & \multicolumn{2}{|c|}{ Paired Rank-Sum Test } & \multicolumn{3}{|c|}{ Standard Value and Number of Exceedances } \\
\hline & $|\mathbf{Z}|$ & $p$ & $\begin{array}{l}\text { Standard } \\
\text { Value }\end{array}$ & $\begin{array}{l}\text { Number of RW } \\
\text { Exceeding the } \\
\text { Standard }\end{array}$ & $\begin{array}{l}\text { Number of PW } \\
\text { Exceeding the } \\
\text { Standard }\end{array}$ \\
\hline Color (TCU) & 5.25 & $<0.01$ & 15 & 0 & 0 \\
\hline Turbidity (NTU) & 0.35 & $>0.05$ & 1 & 0 & 0 \\
\hline $\mathrm{pH}$ & 6.44 & $<0.01$ & $6.5-9.5$ & 0 & 1 \\
\hline Total dissolved solids (mg/L) & 6.47 & $<0.01$ & 1500 & 0 & 0 \\
\hline $\operatorname{Iron}(\mathrm{mg} / \mathrm{L})$ & 1.12 & $>0.05$ & 0.5 & 1 & 2 \\
\hline Copper $(\mathrm{mg} / \mathrm{L})$ & 1.93 & $>0.05$ & 1.0 & 0 & 0 \\
\hline Total hardness $\left(\mathrm{mg} / \mathrm{L} \mathrm{CaCO}{ }_{3}\right)$ & 6.44 & $<0.01$ & 550 & 12 & 0 \\
\hline Sulfide $(\mathrm{mg} / \mathrm{L})$ & 2.61 & $<0.01$ & 0.02 & 1 & 0 \\
\hline Ammonia nitrogen (mg/L N) & 0.73 & $>0.05$ & 0.5 & 28 & 28 \\
\hline $\begin{array}{l}\text { Chemical oxygen demand } \\
\left(\mathrm{mg} / \mathrm{L} \mathrm{O}_{2}\right)\end{array}$ & 5.87 & $<0.01$ & 5 & 7 & 0 \\
\hline Total organic carbon $(\mathrm{mg} / \mathrm{L})$ & 6.23 & $<0.01$ & 5 & 0 & 0 \\
\hline Hexavalent chromium $(\mathrm{mg} / \mathrm{L})$ & 2.25 & $<0.05$ & 0.05 & 2 & 10 \\
\hline Nitrate nitrogen (mg/L N) & 4.87 & $<0.01$ & 20 & 1 & 1 \\
\hline Water quality index & 2.36 & $<0.05$ & 1 & 32 & 26 \\
\hline
\end{tabular}

Among the purified water samples, 30 (45\%) purified water samples complied with drinking water standards. None of the samples had any detectable odor/taste or visible objects. The color, turbidity, total dissolved solids, copper, total hardness, sulfide, COD, and TOC did not exceed their standard values, whereas the remaining indicators exceeded their standard values to varying degrees. Among them, the standard value of ammonia was exceeded most frequently $(42 \%)$, followed by hexavalent chromium (15\%) and iron (9\%) (Table 2, Table S3). Compared with raw water, the rate of compliance with the drinking water standards of purified water was improved ( $8 \%$ ).

The water qualities of the raw and purified water samples were compared using a paired rank-sum test. The differences in the color, COD, total dissolved solids, sulfide concentration, TOC, $\mathrm{pH}$, total hardness, hexavalent chromium concentration, and nitrate nitrogen concentration of the raw and purified water samples were statistically significant $(p<0.05)$. Compared with raw water, the $\mathrm{pH}$ and hexavalent chromium concentration of purified water were significantly increased, while the other parameters were significantly decreased (Table 2, Figure 3). The differences in turbidity and iron, copper, and ammonium nitrogen levels were not statistically significant $(p>0.05)$. The turbidity was lower in the raw water than purified water samples, although the difference was small (Table 2, Figure 3). 


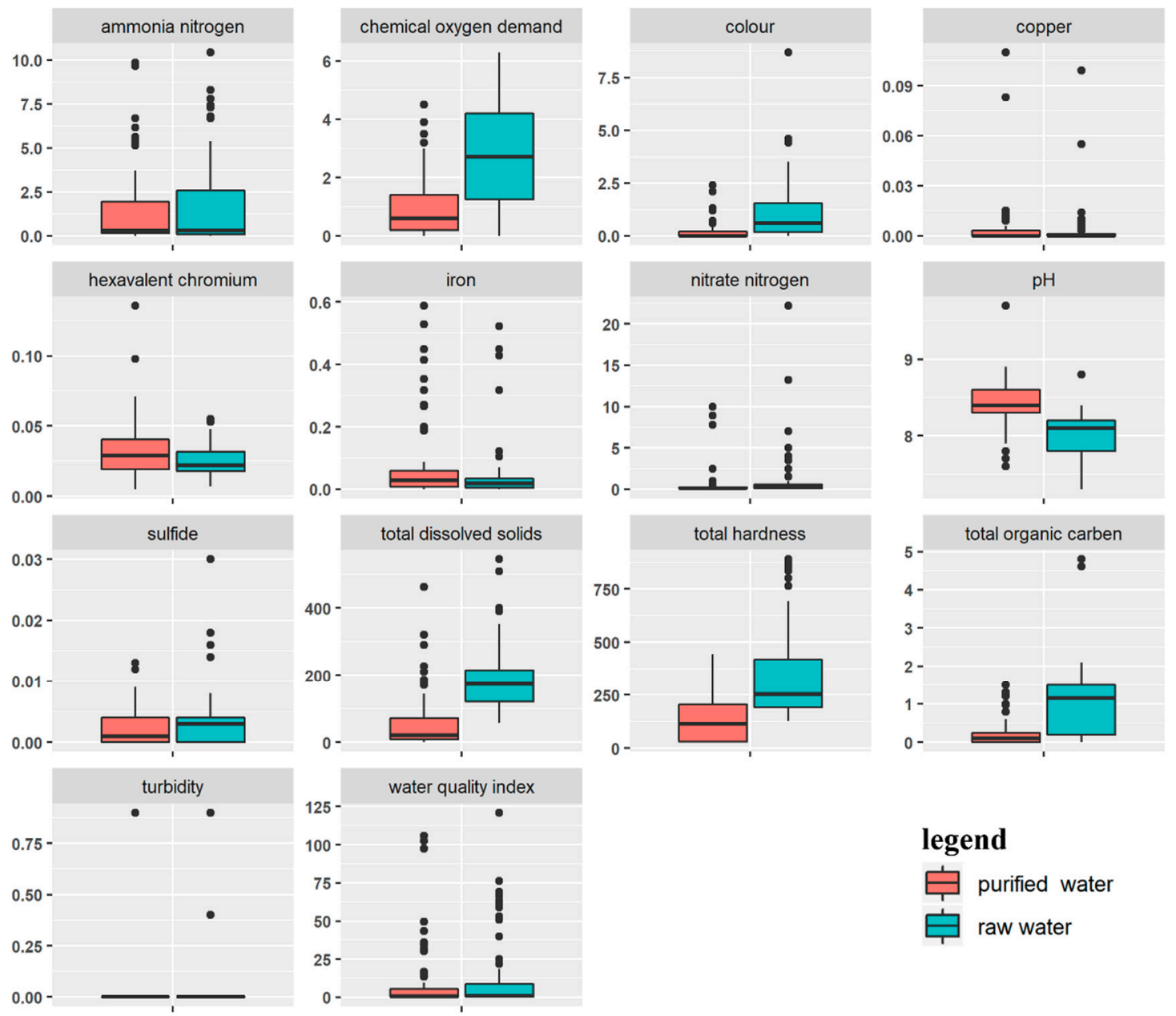

Figure 3. Water quality parameters in the raw and purified water samples $(n=67)$. Units: color (TCU), turbidity (NTU), ammonia nitrogen $(\mathrm{mg} / \mathrm{L} \mathrm{N})$, nitrate nitrogen $(\mathrm{mg} / \mathrm{L} \mathrm{N})$, chemical oxygen demand (COD) $\left(\mathrm{mg} / \mathrm{L} \mathrm{O}_{2}\right)$, total hardness $\left(\mathrm{mg} / \mathrm{L} \mathrm{CaCO}{ }_{3}\right.$, water quality index and $\mathrm{pH}$ (standard units), and other parameters $(\mathrm{mg} / \mathrm{L})$.

The $\mathrm{pH}$ of the purified water was significantly higher than the $\mathrm{pH}$ of the raw water (Table 2, Figure 3). It is generally believed that when a solution passes through a reverse osmosis membrane, water ionization on the permeate side causes a change in $\mathrm{pH}$ to maintain the charge balance and water ionization constant during the filtration process [38]. The cause of water ionization on the permeate side is the difference in permeability of different ions as a consequence of the ion-repellency of the reverse osmosis membrane [38]. The concentrations of some metals were significantly higher in the purified than raw water (Table 2, Figure 3). This may be because the effluent became acidic after it passed through a reverse osmosis membrane, leading to the dissolution of metals in water treatment devices and resulting in higher concentrations of heavy metals and an increased $\mathrm{pH}$. This phenomenon requires further study because it may cause serious health problems. The significant increase in the hexavalent chromium concentration in the effluent water indicates chromium dissolution in the water treatment systems during water purification.

\subsection{Water Quality Index}

The WQI used in this study has certain limitations. For example, when considering the number of parameters exceeding the standard and the extent of their exceedance [20] before and after water treatment, the relative weight of each water quality parameter was not considered. In addition, only 
sensory and general chemical parameters, organic pollution parameters, and toxicity parameters were evaluated. Microbiological parameters were not assessed. These limitations require further study to address them.

In terms of the tested water quality parameters and calculated WQI, a WQI $<1$ indicated that the Chinese drinking water standards [20] were almost always met at desirable levels. A larger WQI value indicated that the standards almost always met the acceptable levels. There were $9 \%$ more samples with a WQI $<1$ in the purified water samples than in the raw water samples (Table 2), indicating that water treatment systems improved the quality of drinking water to some extent, but the improvement was not significant.

The calculated WQI was graded according to the drinking water quality (Table 1). Compared with raw water, there were more purified water samples classified as rank 1 (i.e., "Parameters predominantly meet acceptable levels. No acute threat to human health.") and fewer purified water samples classified as rank 5 (i.e., "Most parameters exceed the acceptable levels. Severe threat to human health.") (Figure 4). This suggests that after the water treatment systems are used, the situation in which parameters are almost always exceed the acceptable levels could be reduced. After using the water treatment systems, some of the water samples that were determined to have desirable levels occasionally exceeded the drinking water standard for certain parameters, but usually by small amounts, could be further purified to meet the drinking water standards. Thus, the water treatment systems can reduce the number and extent of parameters exceeding the standards, and the standards could be met by further removing pollutants in the water. However, the efficacy of this process was not satisfactory.

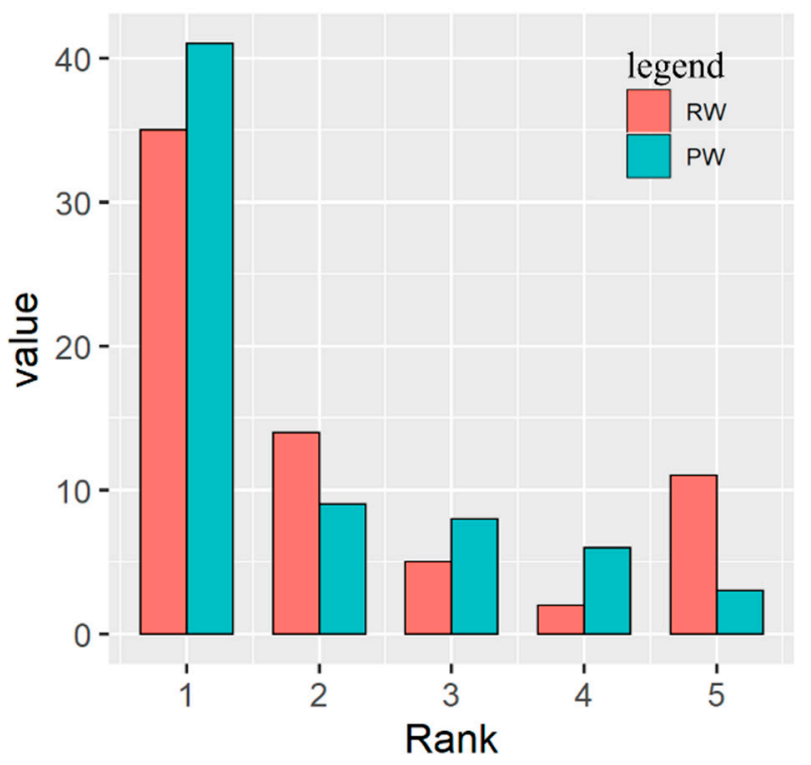

Figure 4. Classification of drinking water quality based on the water quality index (WQI): number of raw water (RW) and purified water (PW) samples with ranks of 1 to 5 (Table 1).

\subsection{Univariate Analysis of the Factors Influencing the WQI of Purified Water}

A univariate analysis was performed using the $\chi^{2}$ test to determine the factors that potentially affected the purified WQI of water treatment systems. The WQI was significantly lower for purified water obtained from purifiers with a filter element that was $<1$ year old compared with $>1$ year old. The difference in the WQI of purified water obtained from decentralized versus small centralized water sources was statistically significant $(p<0.05)$. The effects of the water treatment system service time and WQI of raw water on the WQI of purified water were not significant $(p>0.05)$ (Table S4). This indicates that the service time of the filter element and the type of water supply have significant effects on the overall quality of the purified water, whereas the water treatment system service time and raw water quality have little effect. 


\subsection{Regression Analysis of Factors Influencing the WQI of Purified Water}

A binary logistic regression analysis was performed to identify the factors potentially affecting the WQI of the water obtained from water treatment systems. The WQI of the purified water was used as the dependent variable, and the service time of the water treatment systems, service time of the filter element, WQI of the raw water, and water source type were used as the independent variables. The service time of the filter element had a significant effect on the WQI of the purified water $(p<0.01)$, whereas the effects of the water source type, water treatment system service time, and WQI of the raw water on the WQI of the purified water were not significant $(p>0.05)$ (Table 3).

Table 3. Binary logistic regression analysis of factors influencing the WQI of purified water.

\begin{tabular}{|c|c|c|c|c|c|}
\hline Factor & Category & $x^{2}$ & OR & $95 \%$ CI & $p$ \\
\hline $\begin{array}{l}\text { Water treatment system } \\
\text { service time (years) }\end{array}$ & $\leq 2 />2$ & 0.64 & 0.61 & $0.18-2.05$ & $>0.05$ \\
\hline $\begin{array}{l}\text { Filter element service } \\
\text { time (years) }\end{array}$ & $\leq 1 />1$ & 7.23 & 5.09 & $1.55-16.68$ & $<0.01$ \\
\hline WQI of raw water & $\leq 1 />1$ & 1.04 & 0.54 & $0.16-1.79$ & $>0.05$ \\
\hline Type of water supply & $\begin{array}{c}\text { Decentralized/ } \\
\text { Small centralized }\end{array}$ & 3.48 & 0.06 & $0.23-2.59$ & $>0.05$ \\
\hline
\end{tabular}

The effect of the type of water supply on the purified water quality was not significant in the multivariate analysis $(p>0.05)$. However, the univariate analysis showed that the water source type significantly affected the WQI of the raw water $\left(\chi^{2}=9.604, p<0.05\right)$. This indicates that the water source type does not affect the WQI of the purified water directly, but rather indirectly by influencing other factors. The effect of the filter element service time on purified water quality was consistent between the multivariate and univariate analyses.

In addition, the WQI of raw water from decentralized water supply systems was generally poor, whereas the qualified rate of the purified WQI was $72 \%$, significantly higher compared with small centralized water supply systems with higher raw water quality (Table S4). This also indicates that the type of water supply and WQI of raw water have little influence on the quality of purified water, further suggesting that the quality of purified water obtained from water treatment systems is affected mainly by the service time of the filter element. Even if the raw water quality is not ideal, better purified water quality can be achieved by frequently replacing the filter element.

\subsection{Influence of the Filter Element Service Time on Purified Water Parameters and Removal Rate}

To explore the mechanism of the influence of the filter element service time on the purified water quality, the quality parameters of purified water were compared according to the filter element service time of the water treatment system ( $\leq 1 \mathrm{vs.}>1$ year) using an ANOVA. The ammonia nitrogen content in the purified water was significantly higher when the service time was $>1$ year compared with $\leq 1$ year $(p<0.01)$. The differences in total hardness and sulfide levels according to the filter service time were also significant $(p<0.05)$. The other indicators showed no significant differences $(p>0.05)$ (Figure 5, Table S5). This indicates that the efficacy of the filter element on removing the hardness, sulfide, and ammonia nitrogen from purified water quality is weakened by longer usage of the water treatment system filter element.

The reason for the higher contents of ammonia nitrogen and sulfide after longer usage of the purified water filter element is that the filter eventually reaches saturation. Ammonia nitrogen and sulfide can pass through the reverse osmosis membrane and readily accumulate in the filter and then are released into the water, resulting in the deterioration of the purified water quality. At the same time, the activated carbon adsorption columns provide ideal living conditions for microorganisms, and biofilms can form readily. The water flowing into water treatment devices is well water containing very low levels of dissolved oxygen that is transported through airtight pipes. Therefore, some 
microbial residues in water treatment devices decompose under hypoxic conditions, resulting in increased ammonia nitrogen and sulfide concentrations in the purified water output [39].
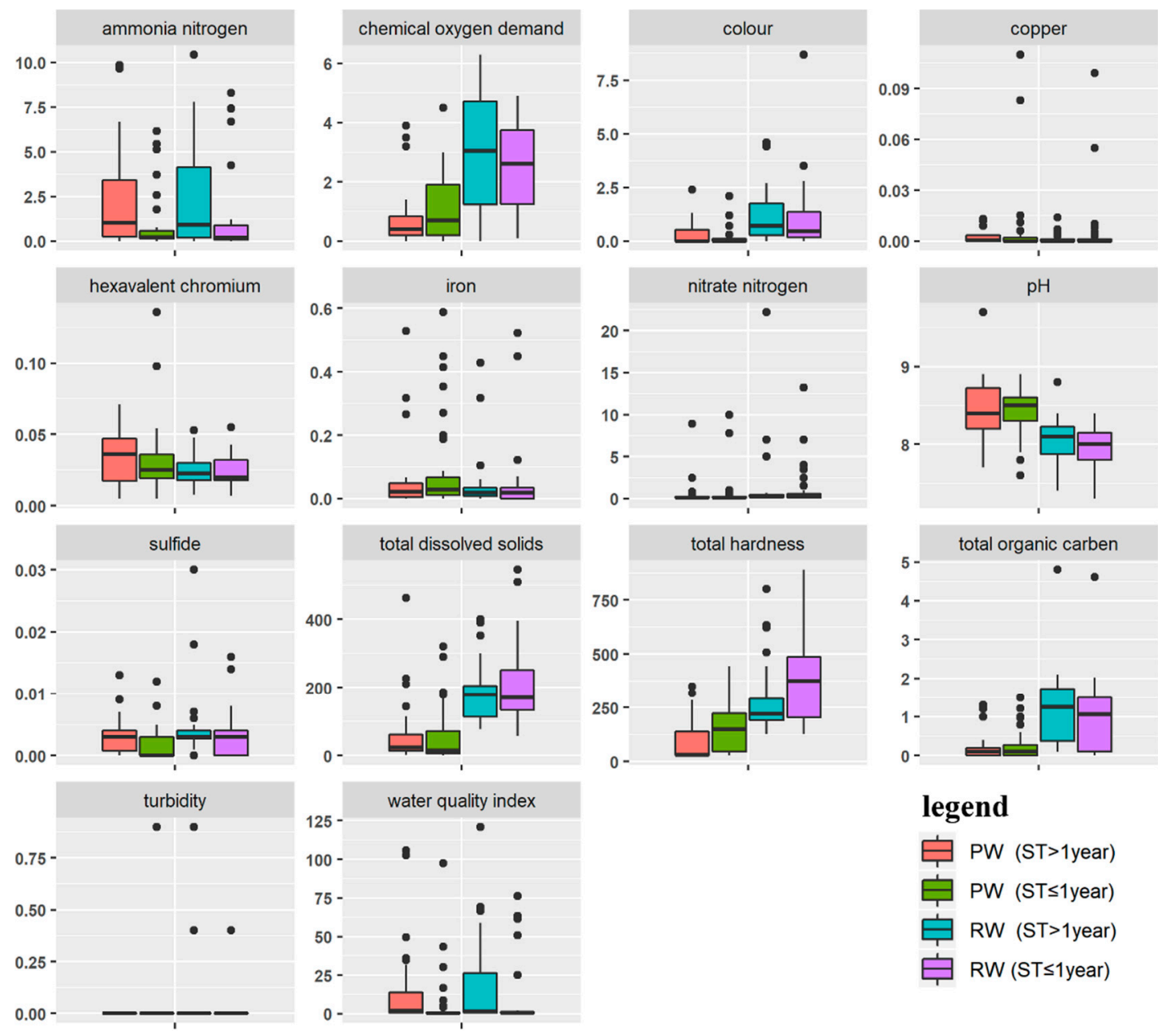

Figure 5. Water quality indicator levels in raw water (RW) and purified water (PW) according to the filter element service time (ST) $(n=67)$. Units: color (TCU), turbidity (NTU), ammonia nitrogen $(\mathrm{mg} / \mathrm{L} \mathrm{N})$, nitrate nitrogen $(\mathrm{mg} / \mathrm{L} \mathrm{N})$, chemical oxygen demand $\left(\mathrm{mg} / \mathrm{L} \mathrm{O}_{2}\right)$, total hardness $\left(\mathrm{mg} / \mathrm{L} \mathrm{CaCO}_{3}\right)$, water quality index and $\mathrm{pH}$ (standard units), and other parameters $(\mathrm{mg} / \mathrm{L})$.

To explore the effects of reverse osmosis water treatment systems from rural areas on water quality parameters, Formula (4) was used to calculate the average removal rate of water treatment systems with different filter element service times.

To meet the actual needs of residents in terms of water use, a faucet providing purified water has been incorporated into the water treatment system. This is a consequence of the overall effect of the water treatment system. However, further research is required to determine the specific effects of reverse osmosis membrane columns and other components in the system. In terms of the overall system, the average removal rates of COD, total dissolved solids, sulfides, and nitrates were higher when the filter service time was $\leq 1$ year compared with $>1$ year. Thus, the removal efficiency of water treatment systems was stronger when the filter element was replaced more frequently [40]. One possible reason for this is leakage from the reverse osmosis membrane after the water treatment system has been used for a long time, which leads to membrane failure [41]. The average rate of sulfide removal was $-18 \%$ versus $-76 \%$ for purifiers with a filter service time $\leq 1$ year versus $>1$ year, respectively (Figure 6). The average removal rate of ammonia nitrogen was higher for purifiers with a filter service time $\leq 1$ year compared with $>1$ year. This indicates the presence of microorganisms 
breeding in the water treatment system or oversaturation of the pollutants adsorbed by the filter material, leading to their release into the purified water. Therefore, the risk of microbial contamination is likely to exist in water treatment systems under non-centralized water supply conditions, and this subject requires further study.

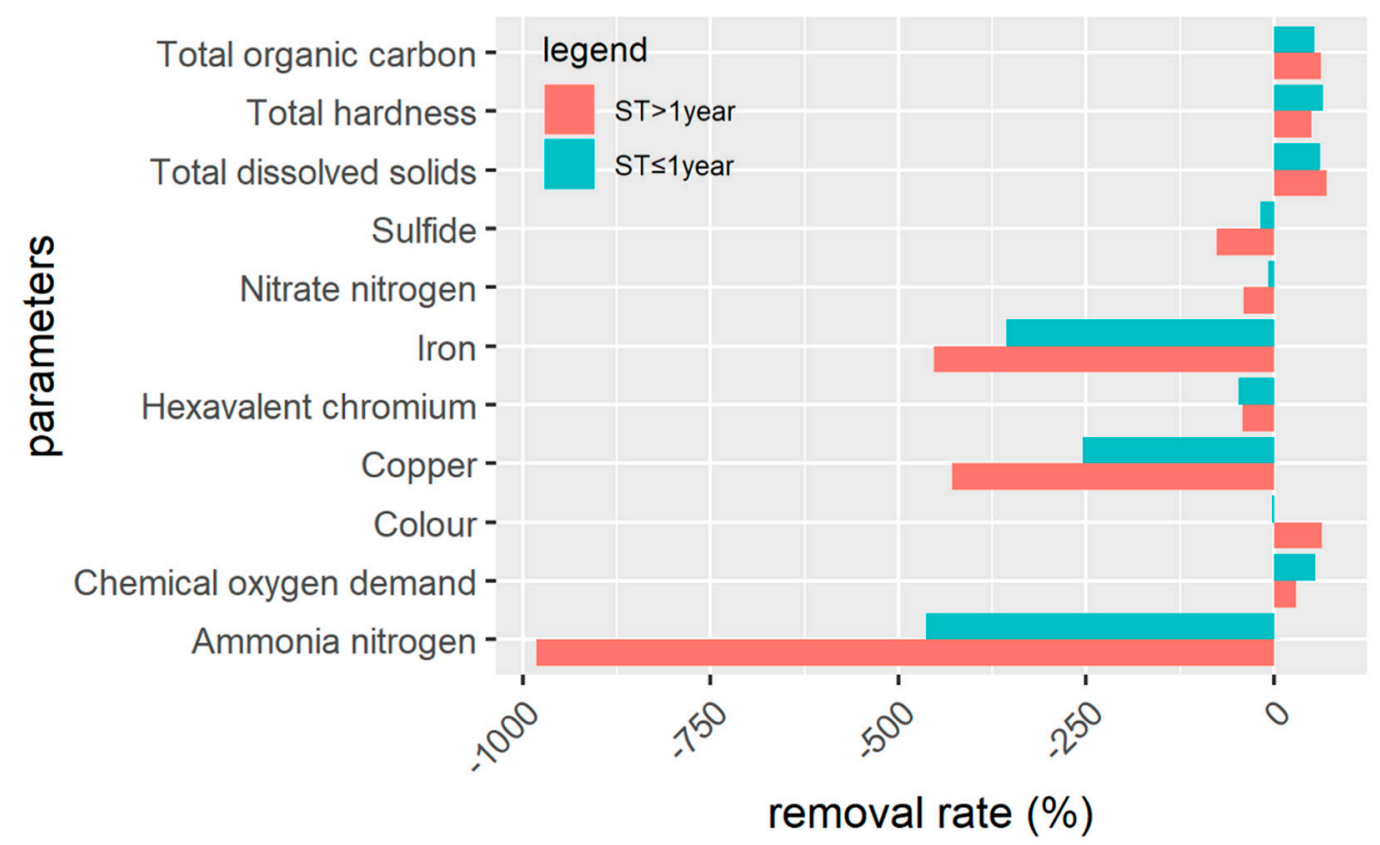

Figure 6. Average removal rate of various pollutants by water treatment systems according to the filter element service time (ST).

Because reverse osmosis membranes generally have a high removal rate of microorganisms, these microorganisms growing in the post-activated carbon adsorption column after the reverse osmosis filter element may enter the purified water [17,42]. In addition, if the reverse osmosis membranes in the water treatment systems are ruptured, microorganisms growing in the activated carbon adsorption columns before the reverse osmosis membranes can also enter the purified water. The shorter the filter element service time, the lower the risk of microbial contamination. Boiling the purified water from the water treatment system before drinking is recommended, as this can effectively reduce the risk of microorganisms.

The average removal rates of iron, copper, and hexavalent chromium from the water treatment systems according to the filter element service time were all negative values, indicating increases in these water quality parameters (Formula (4), Figure 6). This suggests that the interaction between drinking water and the water treatment system may lead to dissolution of iron, copper, chromium, and other metallic elements during the water-purification process [16]. At the same time, the presence of sulfide in the water treatment system may cause corrosion, which is also a potential cause of the increased concentrations of metal indicators in the effluent. In addition, the low quality of the metal components in the water treatment system, which is unsuitable for the purpose in water treatment system, is also a potential cause of the metal concentration in the water. The cause of the increase in metal concentration in purified water requires further study. Potential sources of metal dissolution are the stainless-steel bellows, water pumps, water storage pressure pots, faucets, and other components of the water treatment systems $[16,39,41]$.

\section{Conclusions}

Three significant conclusions were derived from this work. First, the small centralized and decentralized water supplies in the plateau mountainous area of Dali Bai Autonomous Prefecture have 
high levels of organic pollution, rendering the overall water quality unsatisfactory. Compared with the raw water, after installing reverse osmosis water treatment systems, the rate of compliance with drinking water standards improved. Second, single factor, and regression analyses revealed that the most important factor affecting the purified water quality obtained from the water treatment systems was the service time of the filter element. Over time, the ability of the filter element to remove hardness, sulfide, and ammonia nitrogen decreases significantly, affecting the purified water quality. Even if the raw water quality is not ideal, replacing the filter element more frequently could noticeably improve the purified water quality. In addition, the concentrations of iron, copper, chromium, and other metal elements in the purified water increased. Potential causes are the dissolution of metal components in the water treatment system due to interaction between drinking water and the water treatment system (such as corrosion) and the leakage caused by the reverse osmosis membrane failure. Finally, if the main filter element is used for a long period, it is likely to cause the pollutants adsorbed on the oversaturated filter material to be released into the purified water, allowing microorganisms to breed in the activated carbon adsorption columns, which increases the risk of microbial contamination of the purified water. Therefore, it is necessary to replace the filter element of the water treatment system at least once a year to increase the water purification efficacy.

Supplementary Materials: The following are available online at http://www.mdpi.com/2073-4441/12/3/867/s1. Table S1: Rankings of the odor and taste tests. Table S2: Test results of the water quality parameters in the raw water samples $(n=67)$. Table S3: Test results of the water quality parameters in the purified water samples $(n=67)$. Table S4: Analysis of the factors influencing the water quality index (WQI) of purified water. Table S5: Comparison of water quality parameters of purified water according to the service time of the filter element in the water treatment system $(n=67)$.

Author Contributions: Conceptualization and methodology, Z.Z. and X.H.; investigation, P.L., Z.Z., X.L., W.X., X.H.; data curation, P.L., Z.Z.; writing-original draft preparation, Z.Z.; writing-review and editing, S.L., W.Z., C.D., K.L.; visualization, K.L.,W.Z.; supervision, S.L.; funding acquisition, C.D., S.L. All authors have read and agreed to the published version of the manuscript.

Funding: This research was funded by National Science Foundation of China (grant no. 31670522), Yunnan Key Research \& Development Programs (grant nos. 2018BC001, 2019BC001, C6183104, and 2017YLXZ08), College Student Innovation and Entrepreneurship Program in Yunnan University (grant nos. 20180491, 20180494, 201904090 and 201904086).

Acknowledgments: The first author acknowledges the support from Ziyi Suo and Yujing Cai for methods support and the Yunnan University for providing financial support for his research. We gratefully acknowledge Textcheck (a scientific and technical editing service) for revising the English language in our manuscript.

Conflicts of Interest: The authors declare no conflict of interest. The funders had no role in the design of the study; in the collection, analyses, or interpretation of data; in the writing of the manuscript, or in the decision to publish the results.

\section{References}

1. World Health Organization; United Nations Children's Fund. Progress on Drinking Water, Sanitation and Hygiene: 2017 Update and SDG Baselines; World Health Organization: Geneva, Switzerland, 2017.

2. Mkwate, R.C.; Chidya, R.C.G.; Wanda, E.M.M. Assessment of drinking water quality and rural household water treatment in Balaka District, Malawi. Phys. Chem. Earth Parts A/B/C 2017, 100, 353-362. [CrossRef]

3. Grönwall, J.; Danert, K. Regarding Groundwater and Drinking Water Access through A Human Rights Lens: Self-Supply as A Norm. Water 2020, 12, 419. [CrossRef]

4. World Health Organization. World Health Organization Guidelines for Drinking Water Quality; World Health Organization: Geneva, Switzerland, 2011.

5. Légaré-Julien, F.; Lemay, O.; Vallée-Godbout, U.; Bouchard, C.; Dorea, C. Laboratory Efficacy and Disinfection by-Product Formation of a Coagulant/Disinfectant Tablet for Point-of-Use Water Treatment. Water 2018, 10, 1567. [CrossRef]

6. Lou, S.; Huang, W.; Liu, S.; Zhong, G. Scarcity of Drinking Water in Taihu Lake Basin, China: A Case Study of Yixing City. Water 2019, 11, 362. [CrossRef]

7. Guo, L. Ecology_Doing battle with the green monster of Taihu Lake. Science 2007, 317, 1166. [CrossRef]

8. Liu, J.G.; Yang, W. Water Sustainability for China and Beyond. Science 2012, 337, 649-650. [CrossRef] 
9. Yang, H.; Flower, R.J.; Thompson, J.R. Sustaining China's Water Resources. Science 2013, 339, 141. [CrossRef]

10. Li, H.; Cohen, A.; Li, Z.; Zhang, M. The Impacts of Socioeconomic Development on Rural Drinking Water Safety in China: A Provincial-Level Comparative Analysis. Sustainability 2018, 11, 85. [CrossRef]

11. Wu, J.; Man, Y.; Sun, G.; Shang, L. Occurrence and Health-Risk Assessment of Trace Metals in Raw and Boiled Drinking Water from Rural Areas of China. Water 2018, 10, 641. [CrossRef]

12. Zhang, J. The impact of water quality on health: Evidence from the drinking water infrastructure program in rural China. J. Health Econ. 2012, 31, 122-134. [CrossRef]

13. Yu, X.; Geng, Y.; Heck, P.; Xue, B. A Review of China's Rural Water Management. Sustainability 2015, 7, 5773-5792. [CrossRef]

14. Ahmedna, M.; Marshall, W.E.; Husseiny, A.A.; Rao, R.M.; Goktepe, I. The use of nutshell carbons in drinking water filters for removal of trace metals. Water Res. 2004, 38, 1062-1068. [CrossRef] [PubMed]

15. Sobsey, M.D.; Stauber, C.E.; Casanova, L.M.; Brown, J.M.; Elliott, M.A. Point of use household drinking water filtration: A practical, effective solution for providing sustained access to safe drinking water in the developing world. Environ. Sci. Technol. 2008, 42, 4261-4267. [CrossRef] [PubMed]

16. Garfí, M.; Cadena, E.; Sanchez-Ramos, D.; Ferrer, I. Life cycle assessment of drinking water: Comparing conventional water treatment, reverse osmosis and mineral water in glass and plastic bottles. J. Clean. Prod. 2016, 137, 997-1003. [CrossRef]

17. Falkenberg, T.; Saxena, D.; Kistemann, T. Impact of wastewater-irrigation on in-household water contamination. A cohort study among urban farmers in Ahmedabad, India. Sci. Total Environ. 2018, 639, 988-996. [CrossRef]

18. Fahiminia, M.; Mosaferi, M.; Taadi, R.A.; Pourakbar, M. Evaluation of point-of-use drinking water treatment systems' performance and problems. Desalin. Water Treat. 2014, 52, 1855-1864. [CrossRef]

19. Clasen, T.; Menon, S. Microbiological performance of common water treatment devices for household use in India. Int. J. Environ. Health Res. 2007, 17, 83-93. [CrossRef]

20. Chinese Ministry of Health. Standards for Drinking Water Quality; GB5749-2006; Standards Press of China: Beijing, China, 2006. (In Chinese)

21. Dunnette, D.A. A Geographically Variable Water Quality Index Used in Oregon. J. (Water Pol. Control Fed.) 1979, 51, 53-61.

22. Mukate, S.; Wagh, V.; Panaskar, D.; Jacobs, J.A.; Sawant, A. Development of new integrated water quality index (IWQI) model to evaluate the drinking suitability of water. Ecol. Indic. 2019, 101, 348-354. [CrossRef]

23. Iticescu, C.; Georgescu, L.P.; Murariu, G.; Topa, C.; Timofti, M.; Pintilie, V.; Arseni, M. Lower Danube Water Quality Quantified through WQI and Multivariate Analysis. Water 2019, 11, 1305. [CrossRef]

24. Luo, K.; Liu, Y.; Li, H. Fluoride content and distribution pattern in groundwater of eastern Yunnan and western Guizhou, China. Environ. Geochem. Health 2012, 34, 89-101. [CrossRef] [PubMed]

25. Zahedi, S. Modification of expected conflicts between Drinking Water Quality Index and Irrigation Water Quality Index in water quality ranking of shared extraction wells using Multi Criteria Decision Making techniques. Ecol. Indic. 2017, 83, 368-379. [CrossRef]

26. Oliveira, M.D.d.; Rezende, O.L.T.d.; Fonseca, J.F.R.d.; Libânio, M. Evaluating the surface Water quality index fuzzy and its influence on water treatment. J. Water Process Eng. 2019, 32, 100890. [CrossRef]

27. Iqbal, A.B.; Rahman, M.M.; Mondal, D.R.; Khandaker, N.R.; Khan, H.M.; Ahsan, G.U.; Jakariya, M.; Hossain, M.M. Assessment of Bangladesh groundwater for drinking and irrigation using weighted overlay analysis. Groundw. Sustain. Dev. 2020, 10, 100312. [CrossRef]

28. Subba Rao, N.; Sunitha, B.; Adimalla, N.; Chaudhary, M. Quality criteria for groundwater use from a rural part of Wanaparthy District, Telangana State, India, through ionic spatial distribution (ISD), entropy water quality index (EWQI) and principal component analysis (PCA). Environ. Geochem. Health 2019, 42, 579-599. [CrossRef] [PubMed]

29. Najafi Saleh, H.; Valipoor, S.; Zarei, A.; Yousefi, M.; Baghal Asghari, F.; Mohammadi, A.A.; Amiri, F.; Ghalehaskar, S.; Mousavi Khaneghah, A. Assessment of groundwater quality around municipal solid waste landfill by using Water Quality Index for groundwater resources and multivariate statistical technique: A case study of the landfill site, Qaem Shahr City, Iran. Environ. Geochem. Health 2019. [CrossRef] 
30. Marín Celestino, A.E.; Ramos Leal, J.A.; Martínez Cruz, D.A.; Tuxpan Vargas, J.; De Lara Bashulto, J.; Morán Ramírez, J. Identification of the Hydrogeochemical Processes and Assessment of Groundwater Quality, Using Multivariate Statistical Approaches and Water Quality Index in a Wastewater Irrigated Region. Water 2019, 11, 1702. [CrossRef]

31. El Baba, M.; Kayastha, P.; Huysmans, M.; De Smedt, F. Evaluation of the Groundwater Quality Using the Water Quality Index and Geostatistical Analysis in the Dier al-Balah Governorate, Gaza Strip, Palestine. Water 2020, 12, 262. [CrossRef]

32. Yuan, Z.; Wang, Z. Establishment of Drinking Water Quality Index Suitable for Situation of China. Urban Environ. Urban Ecol. 2003, 16, 185-186. (In Chinese)

33. Chinese Ministry of Health. Standard Examination Methods for Drinking Water; GB/T5750-2006; Standards Press of China: Beijing, China, 2006. (In Chinese)

34. RadFard, M.; Seif, M.; Ghazizadeh Hashemi, A.H.; Zarei, A.; Saghi, M.H.; Shalyari, N.; Morovati, R.; Heidarinejad, Z.; Samaei, M.R. Protocol for the estimation of drinking water quality index (DWQI) in water resources: Artificial neural network (ANFIS) and Arc-Gis. MethodsX 2019, 6, 1021-1029. [CrossRef]

35. Hurley, T.; Sadiq, R.; Mazumder, A. Adaptation and evaluation of the Canadian Council of Ministers of the Environment Water Quality Index (CCME WQI) for use as an effective tool to characterize drinking source water quality. Water Res. 2012, 46, 3544-3552. [CrossRef] [PubMed]

36. Ramesh, S.; Sukumaran, N.; Murugesan, A.G.; Rajan, M.P. An innovative approach of Drinking Water Quality Index-A case study from Southern Tamil Nadu, India. Ecol. Indic. 2010, 10, 857-868. [CrossRef]

37. Ponsadailakshmi, S.; Sankari, S.G.; Prasanna, S.M.; Madhurambal, G. Evaluation of water quality suitability for drinking using drinking water quality index in Nagapattinam district, Tamil Nadu in Southern India. Groundw. Sustain. Dev. 2018, 6, 43-49. [CrossRef]

38. Park, H.-G.; Kwon, Y.-N. Investigation on the factors determining permeate $\mathrm{pH}$ in reverse osmosis membrane processes. Desalination 2018, 430, 147-158. [CrossRef]

39. Guan, Q. Investigation and Study of Removal Efficiency and Health Security of Drinking Water Treatment Devices in Schoolsof Haikou City. Master's Thesis, Chinese Center for Disease Contral and Prevention, Beijing, China, 2016. (In Chinese)

40. Smith, E.; El Komos, S. Tap water quality and performance of point-of-use treatment devices in Cairo, Egypt. Water Environ. J. 2009, 23, 119-127. [CrossRef]

41. Wang, K.; Abdalla, A.A.; Khaleel, M.A.; Hilal, N.; Khraisheh, M.K. Mechanical properties of water desalination and wastewater treatment membranes. Desalination 2017, 401, 190-205. [CrossRef]

42. Park, S.K.; Hu, J.Y. Assessment of the extent of bacterial growth in reverse osmosis system for improving drinking water quality. J. Environ. Sci. Health Part A-Toxic/Hazard. Subst. Environ. Eng. 2010, 45, 968-977. [CrossRef]

(C) 2020 by the authors. Licensee MDPI, Basel, Switzerland. This article is an open access article distributed under the terms and conditions of the Creative Commons Attribution (CC BY) license (http://creativecommons.org/licenses/by/4.0/). 